\title{
Benign occipital epilepsy
}

INSERM

\section{Source}

INSERM. (1999). Orphanet: an online rare disease and orphan drug data base. Benign occipital epilepsy. ORPHA:25968

Benign occipital epilepsy is a rare, genetic neurological disorder characterized by visual seizures and occipital epileptiform paroxysms reactive to ocular opening which present in infancy to mid-adolescence. Vomiting, tonic eye deviation and impairment of consciousness are typically associated with the Panayiotopoulos type, while visual hallucinations, ictal blindness and post-ictal headache are commonly observed in the Gastaut type. Electroencephalog raphic findings in both types are similar and include bilateral, synchronous, high voltage spike-wave complexes in a normal background activity located predominantly in the occipital lobes. 